\title{
Apoptosis-mediated antiproliferation of A549 lung cancer cells mediated by Eugenia aquea leaf compound 2',4'-dihydroxy-6'-methoxy-3',5'-dimethylchalcone and its molecular interaction with caspase receptor in molecular docking simulation
}

\author{
YUNI ELSA HADISAPUTRI ${ }^{1,2}$, NONI CAHYANA ${ }^{2,3}$, MUCHTARIDI MUCHTARIDI $^{4}$, \\ RONNY LESMANA $^{2,5}$, TAOFIK RUSDIANA ${ }^{6}$, ANIS YOHANA CHAERUNISA ${ }^{6}$, \\ IRNA SUFIAWATI $^{7}$, TINA ROSTINAWATI ${ }^{1}$ and ANAS SUBARNAS ${ }^{3}$
}

${ }^{1}$ Department of Pharmaceutical Biology, Faculty of Pharmacy; ${ }^{2}$ Division of Biological Activity, Laboratorium Central;

${ }^{3}$ Department of Pharmacology and Clinical Pharmacy, Faculty of Pharmacy; ${ }^{4}$ Department of Pharmaceutical Analysis and Medicinal Chemistry, Faculty of Pharmacy; ${ }^{5}$ Division of Physiology, Department of Basic Science, Faculty of Medicine; ${ }^{6}$ Department of Pharmaceutics and Pharmaceutical Technology, Faculty of Pharmacy;

${ }^{7}$ Department of Oral Medicine, Faculty of Dentistry, Universitas Padjadjaran, West Java 45363, Indonesia

Received May 2, 2019; Accepted February 7, 2020

DOI: 10.3892/ol.2020.11466

\begin{abstract}
In a previous study, 2',4'-dihydroxy-6'-methoxy3',5'-dimethylchalcone (ChalcEA) isolated from the leaves of Eugenia aquea was reported to inhibit proliferation of the breast adenocarcinoma MCF7 cell line and to promote apoptosis via activation of poly(adenosine diphosphate-ribose) polymerase protein. The present study aimed to evaluate the inhibitory effect of ChalcEA on the proliferation of A549 lung cancer cells using a 3-(4,5-dimethylthiazol-2-yl)-5-(3-carbo xylmethoxyphenyl)-2-(4-sulfophenyl)-2H-tetrazolium assay, and to examine the ability of ChalcEA to induce apoptosis through activation of the caspase cascade signaling pathway in a western blotting assay. The results revealed that ChalcEA inhibited proliferation of the A549 lung cancer cell lines in a time- and dose-dependent manner with $\mathrm{IC}_{50}$ values of 25.36 and $19.60 \mu \mathrm{M}$ for 24 and $48 \mathrm{~h}$ treatments, respectively. Western blot
\end{abstract}

Correspondence to: Professor Anas Subarnas, Department of Pharmacology and Clinical Pharmacy, Faculty of Pharmacy, Universitas Padjadjaran, Jl. Raya Bandung-Sumedang KM.21, Jatinangor, West Java 45363, Indonesia

E-mail: aasubarnas@yahoo.co.id

\begin{abstract}
Abbreviations: ChalcEA, 2',4'-dihydroxy-6'-methoxy-3',5'dimethylchalcone; PARP, poly(adenosine diphosphate-ribose) polymerase; MTS, 3-(4,5-dimethylthiazol-2-yl)-5-(3-carboxylmet hoxyphenyl)-2-(4-sulfophenyl)-2H-tetrazolium; E. aquea, Eugenia aquea; $\mathrm{MB}$, 4-methyl-benzenesulfonamide
\end{abstract}

Key words: 2',4'-dihydroxy-6'-methoxy-3',5'-dimethylchalcone, Eugenia aquea, A549, caspase-cascade, molecular docking analysis indicated that ChalcEA exerted its anti-proliferative effects by promoting apoptosis via the activation of caspase- 9 and caspase-3. Based on in silico results, ChalcEA with the binding energy of $-6.53 \mathrm{kcal} / \mathrm{mol}$ could compete better than 4-methyl benzenesulfonamide $(-6.43 \mathrm{kcal} / \mathrm{mol})$ as an inhibitor of caspase-3 (PDB: 2XYG). ChalcEA has potential since it has three hydrophobic features. These results provided a basis for further study of ChalcEA as an active compound for anticancer therapeutics.

\section{Introduction}

Cancer is one of the most malignant diseases that may affect different parts of the body and remains an extremely serious life-threatening disease for humans (1). This disease is characterized by a rapid and uncontrolled growth of abnormal cells, which may mass together to form a tumor or proliferate throughout the body, initiating abnormal growth at other sites (2). Among the various types of cancer, lung cancer is known to be the most common cause of cancer-associated mortality worldwide (3). Central and Eastern Europe is the region with highest mortality rate (3).

In general, treatment of cancer in humans uses chemotherapeutic agents in addition to surgery and radiation (2). Chemotherapeutic agents for cancer, including breast cancer, often provide temporary relief of symptoms, prolongation of life and occasionally cures (2). However, they often result in serious side effects and can cause excessive damage to normal cells (4). This has prompted continuous efforts of researchers to identify novel anticancer compounds through chemical synthesis, as well as isolation from plant origins. A number of compounds derived from medicinal plants have potential cytotoxicity against several types of cancer 
cells in anticancer evaluation in vitro or in vivo (5-7). Plants consumed by primates are assumed to be a promising source of therapeutic agents for the management of human diseases and a series of investigations have been conducted and provided novel findings of their cytotoxicity against breast cancer cell lines (1,8-10). Kaempferol-3- $O$-rhamnoside isolated from the leaves of Schima wallichii, a plant commonly consumed by primates, exhibits inhibitory activity against MCF7 breast cancer cell proliferation through the activation of the caspase cascade signaling pathway (8). Subarnas et al (9) evaluated antiproliferative effects of 42 species of primate-consumed plants against MCF7 human breast cell lines using an MTT bioassay and revealed that some plant extracts have strong inhibitory activity against MCF7 cell proliferation. Furthermore, 2',4'-dihydroxy-6'-methoxy-3',5'-dimethylchalcone (ChalcEA), isolated from the leaves of Eugenia aquea (E. aquea), inhibits the proliferation of MCF7 cell lines and promotes apoptosis via the activation of poly(adenosine diphosphate-ribose) polymerase (PARP) protein (10). Additionally, a friedolanostane triterpenoid from Garcinia celebica leaves inhibits the growth of MCF7 cells through induction of apoptosis and downregulation of the oncogene Akt (1).

The present study was conducted to clarify the inhibitory activity of ChalcEA against cell proliferation and molecular pro-apoptotic activity through activation of the caspase cascade of A549 lung cancer cells. Furthermore, a molecular interaction of ChalcEA with caspase-3 was also evaluated using a molecular docking simulation.

\section{Materials and methods}

Plant materials. The leaves of E. aquea were collected from Pangandaran Beach Conservation Area (Pangandaran, West Java, Indonesia). Determination of the plant species was performed by the Department of Biology of Padjadjaran University (Bandung, West Java, Indonesia). The leaves were dried in the open air for 4-5 days, away from direct sunlight.

Isolation of ChalcEA of E. aquea. ChalcEA was obtained from the leaves of E. aquea. The isolation of the compound has been reported previously by Subarnas et al (10) and its structure was shown in Fig. 1. This compound was named 2',4'-dihydroxy-6'-methoxy-3',5'-dimethylchalcone (10).

Cell culture and treatment. The A549 lung cancer cell line was purchased from the American Type Culture Collection. The cells were cultured in RPMI-1640 medium (Sigma-Aldrich; Merck KGaA) supplemented with $10 \%$ fetal bovine serum (Sigma-Aldrich; Merck KGaA) and $100 \mathrm{U} / \mathrm{ml}$ penicillin and $100 \mu \mathrm{g} / \mathrm{ml}$ streptomycin (Sigma-Aldrich; Merck KGaA). Cells were cultured under standard culture conditions in a $\mathrm{CO}_{2}$ incubator with $5 \% \mathrm{CO}_{2}$ at $37^{\circ} \mathrm{C}$. The medium was replaced once every 2 days. Cell condition were checked using an Axio Vert A.1 for Biology (Zeiss AG) inverted microscope (magnification, $\mathrm{x} 200$ ).

Cell proliferation assay using Cell counting Kit-8. Cell proliferation analysis was performed using an MTS assay on cells in the presence of various concentrations of ChalcEA (1.9-1,000 $\mu \mathrm{g} / \mathrm{ml})$. Cultured cells $\left(1 \times 10^{4} /\right.$ well $)$ were plated into 96 -well microtiter plates in a final volume of $100 \mu \mathrm{l} /$ well. Subsequent to the initial cell seeding, various concentrations of ChalcEA $(1.9,3.9,7.8,15.6,31.25,62.5,125,250,500$ and $1,000 \mu \mathrm{g} / \mathrm{ml}$ ) were added and the cells were incubated for 24 to $48 \mathrm{~h}$ at $37^{\circ} \mathrm{C}$. After ChalcEA treatment was halted by the replacing media, $10 \mu \mathrm{l} /$ well of Cell Counting Kit-8 (Dojindo Molecular Technologies, Inc.) were added into each well and incubated for $3 \mathrm{~h}$ at $37^{\circ} \mathrm{C}$ in standard culture conditions according to the manufacturer's protocol. The cell proliferation rate was determined by measuring absorbance at a wavelength of $450 \mathrm{~nm}$ (reference $620 \mathrm{~nm}$ ) using an Infinite ${ }^{\circledR} 200$ PRO microtiter plate reader (Tecan Group, Ltd.). All samples were tested in triplicate. CPI rate was calculated according to the method stated in the manufacturer's protocol.

Cell extraction and western blotting. A total of $1 \times 10^{6}$ A549 cells and $1 \times 10^{6}$ untreated control cells were treated with ChalcEA $(25 \mu \mathrm{M})$ for $12,24,36$ and $48 \mathrm{~h}$. Cells were washed twice using a cold PBS buffer and the cell lysate was prepared using RIPA lysis buffer (EMD Millipore; Sigma-Aldrich; Merck KGaA). The Pierce ${ }^{\mathrm{TM}}$ Modified Lowry Protein assay kit (Thermo Fisher Scientific Inc.) was used to measured total protein that extracted from A549 cells according to the manufacturer's protocol. A total of $25 \mu \mathrm{g} /$ lane A549 cell protein extracts were loaded on a $30 \%$ polyacrylamid gel (Invitrogen; Thermo Fisher Scientific, Inc.) and electrotransferred onto a Amersham ${ }^{\mathrm{TM}}$ Protran $^{\mathrm{TM}} 0.45-\mu \mathrm{m}$ nitrocellulose membrane (GE Healthcare Life Sciences). Membranes were blocked using $5 \%$ skimmed milk and agitated at $25^{\circ} \mathrm{C}$ for $30 \mathrm{~min}$. Apoptosis-associated proteins were analyzed using immunoblot analysis with caspase-3 (cat. no. AF-605NA; 1:1,000; R\&D Systems, Inc.) and caspase-9 antibodies (cat. no. AF-8301; 1:1,000; R\&D Systems, Inc.) incubated in $4^{\circ} \mathrm{C}$ for 24 h. $\beta$-actin (cat. no. 4967; 1:15,000; Cell Signaling Technology, Inc.) served as the loading control for $1 \mathrm{~h}$ incubation in room temperature. Mouse anti-goat IgG horseradish peroxidase-conjugated antibodies (cat. no. sc-2354; 1:10,000; Santa Cruz Biotechnology, Inc.) served as secondary antibody for $90 \mathrm{~min}$ incubation in room temperature. Visualization of protein bands was conducted using chemiluminesence reagent (GE Healthcare). Bands on the membrane were detected and measured using a C-DiGit ${ }^{\circledR}$ Blot scanner (LI-COR Biosciences) with Image Studio Digits v. 5.2 (LI-COR Biosciences) for band density measurement. All samples were tested in triplicate.

Molecular docking simulation. The X-ray crystallography derived caspase-3 (CAS329306) complex with 4-methyl-benzenesulfonamide (MB) was obtained from Protein Data Bank (PDB ID: 2XYG; https:/www.rcsb.org/ structure/2XYG) (11). The macromolecule and ligand structures were extracted using LigandScout version 4.2 Advanced (Inte:Ligand $\mathrm{GmbH}$ ). The molecular docking simulation methods were modified according to a previous study (12). All ligands (Met61, Arg64, Ser120, His121, Gly122, Glu123, Phe128, Ala162, Cys163, Thr166, Tyr204 and Arg207) and the estrogen receptor $\alpha(\mathrm{ER} \alpha)$ receptor were prepared for docking using AutoDockTools version 1.5.6. (The Scripps Research Institute) The ligands and the receptor were protonated. The default charges energy parameters were allocated to the protein and ligand atoms. A grid box comprised 40x40x40 points 
<smiles>COc1c(C)c(O)c(C)c(O)c1C(=O)/C=C/c1ccccc1</smiles>

Figure 1. Structure of 2',4'-dihydroxy-6'-methoxy-3',5'-dimethylchalcone.

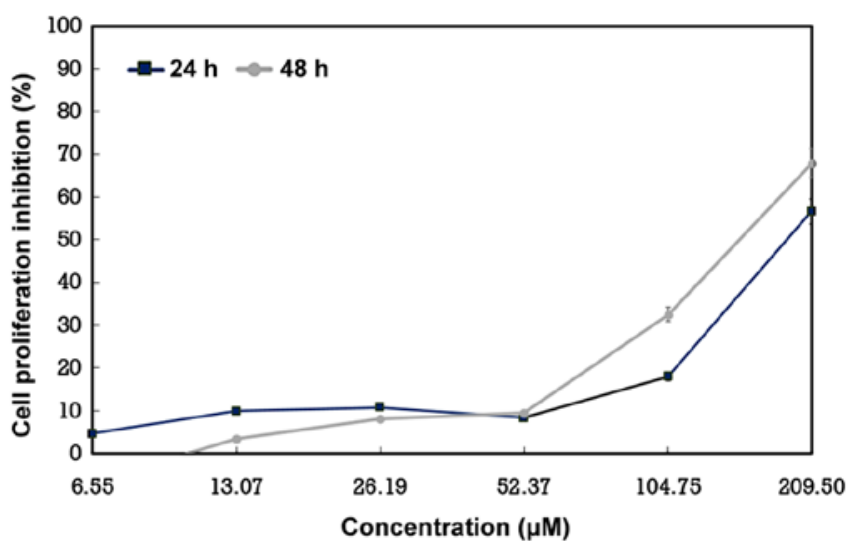

Figure 2. Effect of ChalcEA on the proliferation of A549 lung cancer cells when treated with various concentrations of ChalcEA for 24 and $48 \mathrm{~h}$. Data are presented as mean \pm standard deviation. ChalcEA, 2',4'-dihydroxy-6'-methoxy-3',5'-dimethylchalcone.

spaced by $0.375 \AA$ that was centered on the androgen receptor (AR) active site $(x=36.357 ; y=38.829$; and $z=32.088)$. Autogrid was used to calculate grid box of binding affinity of each of the ligand atom types. The resulting docked conformations were clustered using a root-mean-square deviation tolerance of $1.0 \AA$. The ligand conformation with the lowest free energy of binding, selected from the most favored cluster as sorted by scores and by binding position, was selected for further analysis. The ligand-interaction features for each pose within the binding pocket were determined automatically using LigandScout Advanced version 4.2.

Structure-based 3D-pharmacophore modeling. A 3D structure-based pharmacophore model was derived automatically from the X-ray derived structure of PDB ID: 2AX6 in complex with hydroxyflutamide (HF), using Ligandscout version 4.2 Advanced based on a previous study (13).

Statistical analysis. Quantitative data was obtained using the band scanner Image Studio Digits v. 5.2 (LI-COR Biosciences). Data are presented as mean \pm standard deviation. After calculation of the normality of the data using a stem and leaf plot, one-way ANOVA followed with Tukey's post hoc test was performed to assess the statistical significance of more than two groups. The measurements were assessed in triplicate. SPSS version 26 (IBM Corp.) was used for all statistical analyses. $\mathrm{P}<0.05$ was considered to indicate a statistically significant difference.
A
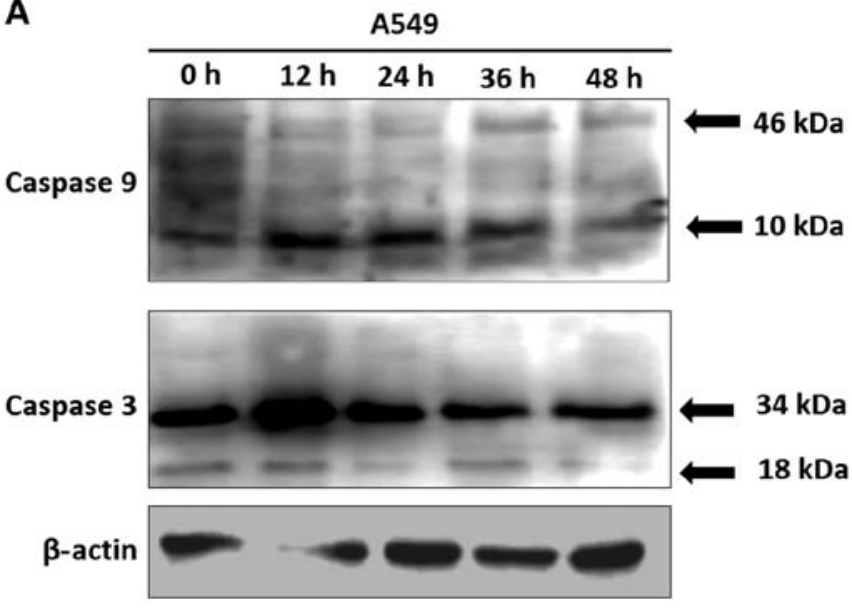

B

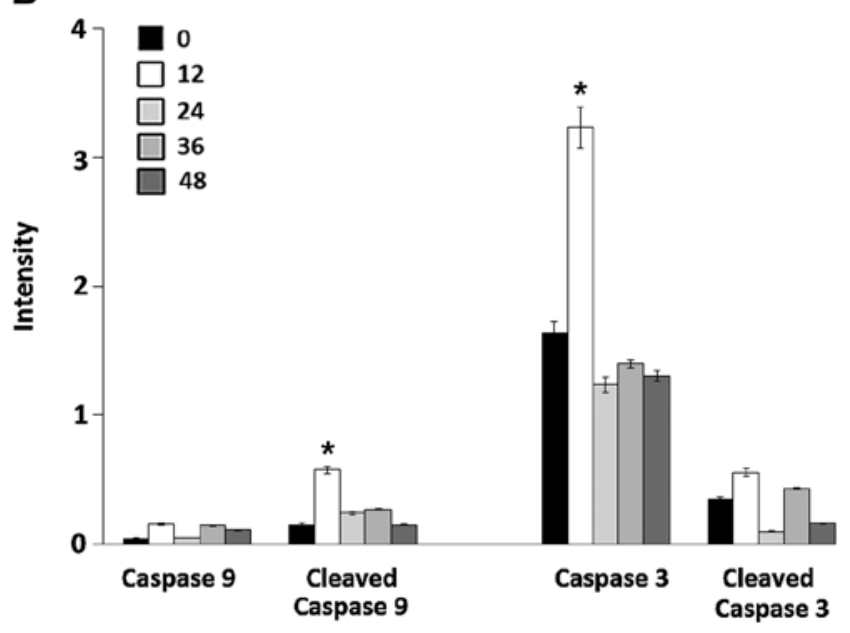

Figure 3. Western blot analysis of caspase cascade-related proteins in A549 lung cells treated with ChalcEA. (A) Changes in the expression levels of caspase- 9 and -3 were determined in A549 cells treated with ChalcEA at $0,12,24,36$ and $48 \mathrm{~h}$. Expression levels of cleaved caspase-9 and -3 were increased at $12 \mathrm{~h}$, followed by elevated caspase-3 expression levels suggesting that apoptosis was occuring. (B) Expression levels of caspase-9, cleaved caspase-9, caspase-3 and cleaved caspase-3. Quantitative data of band density measured using Image Studio Digits v. 5.2 (LI-COR Biosciences). Data are presented as mean \pm standard deviation. One-way ANOVA followed by Tukey's post-hoc test was performed. ${ }^{*} \mathrm{P}<0.05$. ChalcEA, 2',4'-dihydroxy-6'-methoxy-3',5'-dimethylchalcone.

\section{Results}

Inhibitory activity of ChalcEA against proliferation of A549 cells. ChalcEA was evaluated for its effect on the proliferation of A549 lung cancer cells in a proliferation assay. The evaluation revealed a dose- and time-dependent inhibition of cell proliferation by the compound. The compound strongly inhibited the proliferation of A549 cells in 24 and $48 \mathrm{~h}$ examinations with an $\mathrm{IC}_{50}$ value of 25.36 and $19.60 \mu \mathrm{M}$, respectively (Fig. 2).

Proapoptotic activity of ChalcEA. The proliferation assay results revealed strong inhibitory activity of cell proliferation by ChalcEA against A549 cells demonstrated morphologically, for example cells broke into small pieces (Fig. S1). Therefore, caspase-inducing activity of the compound was examined in the A549 cell line. As shown in Fig. 3, expression levels of 
Table I. Molecular docking and pharmacophore modelling results.

\begin{tabular}{lcll}
\hline Compounds & $\begin{array}{c}\text { Free binding energy } \\
\text { (kcal/mol }\end{array}$ & $\begin{array}{c}\text { Hydrogen bond } \\
\text { interaction }\end{array}$ & \multicolumn{1}{c}{$\begin{array}{c}\text { Pharmacophore } \\
\text { features }\end{array}$} \\
\hline 4-methyl-benzenesulfonamide (MB) & -6.43 & His121, Tyr166 & 3HBA, 2Hy, NI \\
2',4'-dihydroxy-6'-methoxy-3', & -6.53 & His121, Cys163, Tyr166, & 1 HBD, 2 HBA, 3 Hy \\
5'-dimethylchalcone & & Arg207 & \\
\hline
\end{tabular}

HBD, hydrogen bond donor; HBA, hydrogen bond receptor; Hy, hydrophobic; NI, negative ionizable.

active fragments of caspase- 9 and caspase- 3 were increased in A549 cells at $12 \mathrm{~h}$, including caspase-9 fragments with $46 \mathrm{kDa}$ $(\mathrm{P}<0.0001)$ and $10 \mathrm{kDa}(\mathrm{P}=0.0001)$ and caspase 3 fragments with $34 \mathrm{kDa}(\mathrm{P}=0.0001)$ and $18 \mathrm{kDa}(\mathrm{P}=0.0001)$. These results suggested that the inhibition of A549 human lung cancer cell proliferation by ChalcEA was mediated by the induction of apoptosis through activation of caspase- 9 and caspase-3.

Molecular docking and pharmacophore modelling of ChalcEA. Based on in vitro studies, molecular docking was used to demonstrate ChalcEA interaction with caspase-3 receptors by inhibiting ER $\alpha$. As shown in Table I, ChalcEA had a lower binding energy affinity than 4-methyl-benzenesulfonamide (MB). ChalcEA formed a hydrogen bond interaction with amino acid residues of His121, Cys163, Tyr166 and Arg207 (Fig. 4B and D), whereas MB only had hydrogen bond interaction with His121 and Tyr166 (Fig. 4A and C). Furthermore, Fig. 4C revealed that $\mathrm{MB}$ induced conformation changes of Tyr204. ChalcEA also has hydrogen bond interaction at the Cys163 and Arg207 sites that not only conformationally changes Tyr204 but also stabilizes via interaction with Glu123 and Gly122. Moreover the interactions were stabilized by a $\pi-\pi$ interaction between the aromatic rings of ChalcEA and Phe128-Met61 (Fig. 4B and D). The ChalcEA bond with caspase-3 can be seen in Fig. 4E. In the pharmacophore results, ChalcEA was mapped well in two hydrophobics (yellow ball) with pharmacophoric model of $\mathrm{HF}$ as indicated in Fig. 4D. However, ChalcEA has potential to bind amino acid residues from receptors since this compound has three hydrophobic regions, two hydrogen bond receptors (red) and one hydrogen bond donor (green).

\section{Discussion}

Previously, the compound ChalcEA obtained from the leaves of E. aquea has been shown to have antiproliferation activity in MCF7 cells and to promote proapoptotic activity via PARP protein activation (10). However, the present study investigated the effects of ChalcEA on the growth of A549 lung cancer cells as lung cancer is known as a malignant lung tumor characterized by uncontrolled cell growth in tissues of the lung (14). Worldwide, lung cancer is the most common cancer among men in terms of both incidence and cancer-associated mortality, and among women it has the third highest incidence in 2008 and $2012(3,15)$. In 2012, there were 1.82 million new cases of lung cancer globally and 1.56 million cancer-associated deaths were due to lung cancer, representing $\sim 19.4 \%$ of all cancer-associated deaths (15). ChalcEA is also hypothesized to be effective in inhibition of the growth of A549 lung cancer cells (13). The present study demonstrated that the compound showed significant inhibition of A549 cell proliferation with $\mathrm{IC}_{50}$ values of 25.36 and $19.60 \mu \mathrm{M}$ for 24 and $48 \mathrm{~h}$ treatments. The results of the present study suggested that the underlying molecular mechanism of this proapoptotic activity occurred through the activation of caspase- 9 and caspase- 3 . Furthermore, a molecular interaction of ChalcEA with caspase-3 was evaluated using molecular docking simulation.

The present study showed that ChalcEA isolated from E. aquea leaves significantly inhibited A549 cell proliferation. This evidence was in line with a previous study which reported that the addition of ChalcEA isolated from the buds of Cleistocalyx operculatus resulted in inhibition of lung cancer GLC-82 xenografts (13). ChalcEA also significantly inhibits the growth of human liver cancer SMMC-7721 cells and may induce apoptosis of SMMC-7721 cells in vitro (16). The antitumor effects of this compound have also been demonstrated in vivo in a solid human tumor xenograft mouse model using human liver cancer SMMC-7721 cells (17). Additionally, ChalcEA inhibits subcutaneous tumor growth of human hepatocarcinoma Be17402 cells (18); however, reports of ChalcEA $\mathrm{IC}_{50}$ values in cancer cells remain limited.

The results of the present study suggested that ChalcEA triggered cell death intrinsically in A549 cells via the mitochondrial caspase-9 signaling pathway and activation of caspase- 3 at $12 \mathrm{~h}$. These results were in agreement with those of a previous study which stated that ChalcEA activates Akt before $12 \mathrm{~h}$ which then triggers cell death intrinsically through caspase-9 activation, in a xenograft model (13). Activation of caspase-3 marks the occurrence of apoptosis and cell death (19). This evidence of the underlying molecular mechanism may explain the effect of ChalcEA against cancer angiogenesis and tumor growth in a solid tumor xenograft in mouse model $(13,17)$.

Based on previous in vitro studies, ChalcEA interaction with caspase- 3 receptors has been identified by inhibiting ER $\alpha$ which then inhibits Akt to activate caspase-9 $(12,17)$. Caspases function as mediators of programmed apoptosis (19). Caspase- 3 is an activated death protease, catalyzing the specific cleavage of a number of cellular proteins, for example PARP, DFF40, DFF45, $\alpha$-Fodrin and Gelsolin, that trigger cell DNA fragmentation and blebbing (19). Caspase-9 can directly cleave and activate caspase-3 and caspase-7 (20).

In the present study, ChalcEA was investigated as a prospective drug candidate which should be further evaluated and 
A

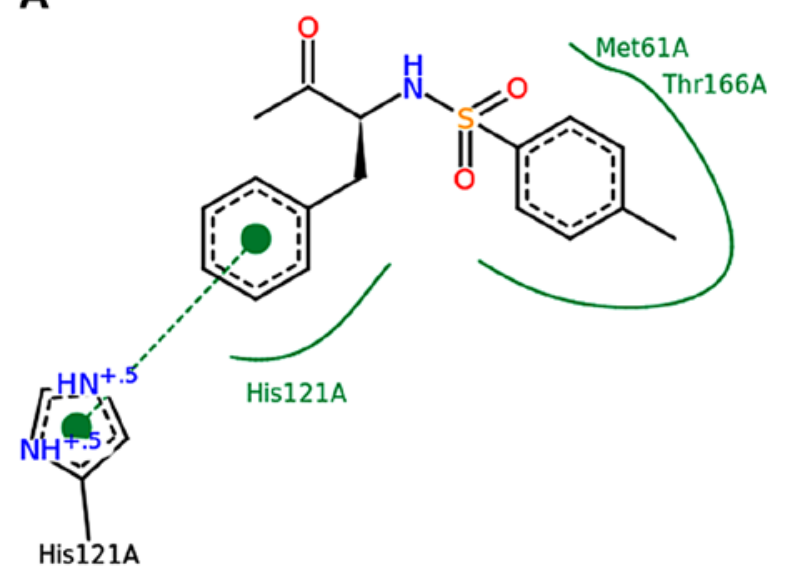

B

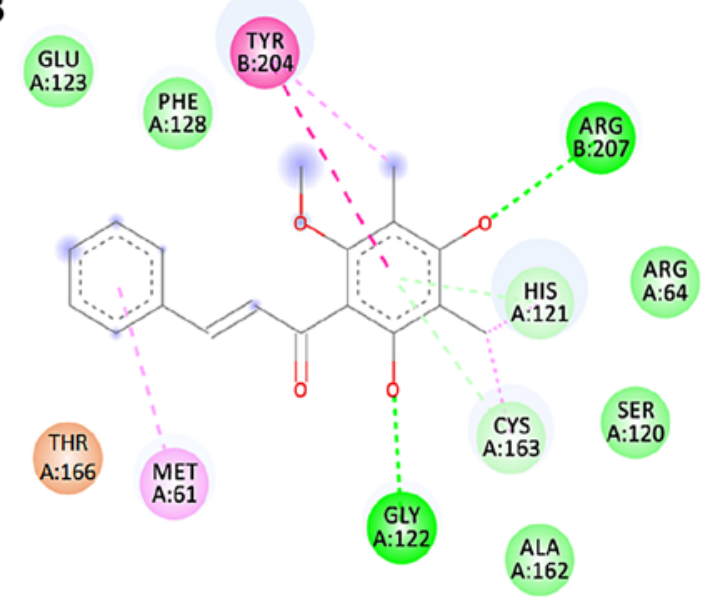

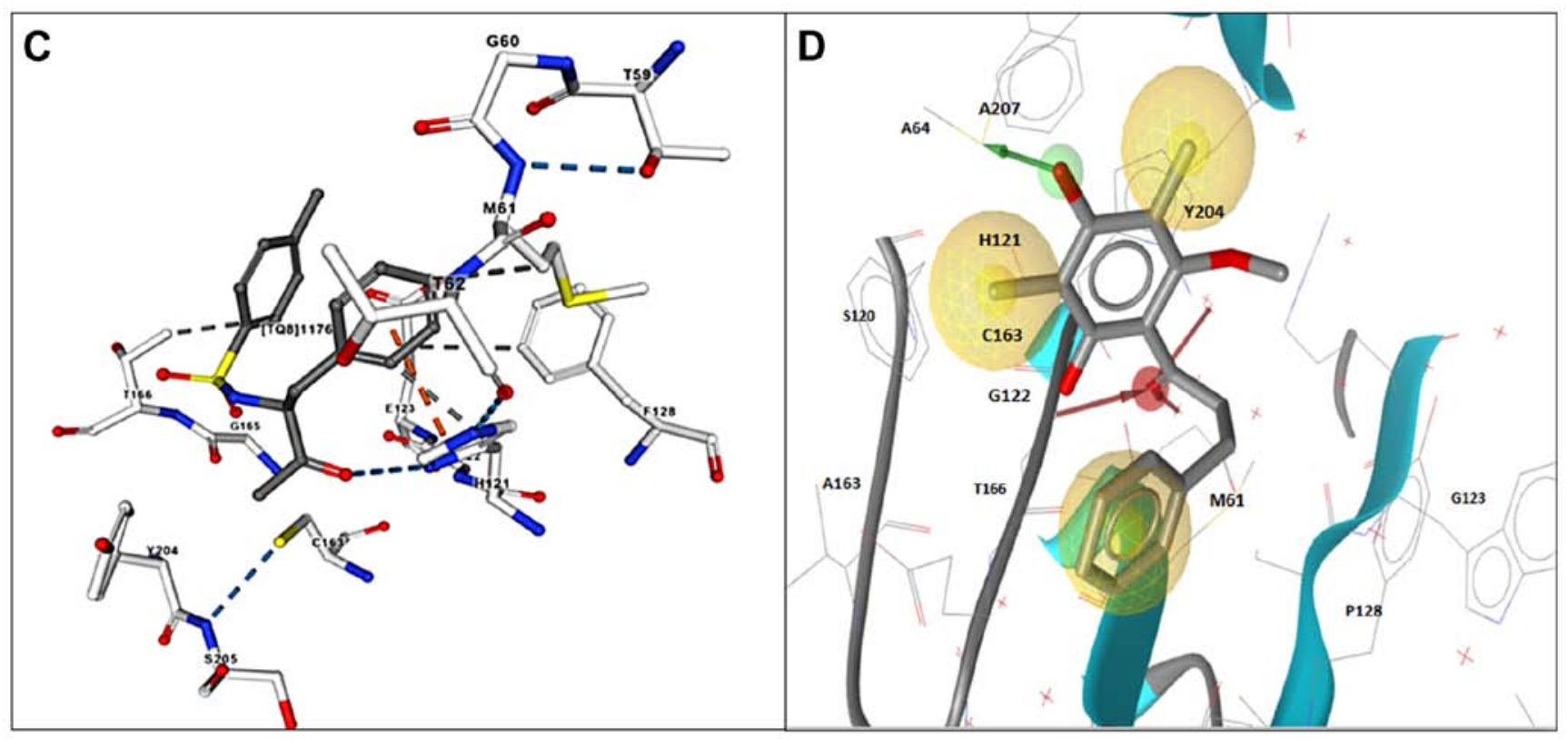

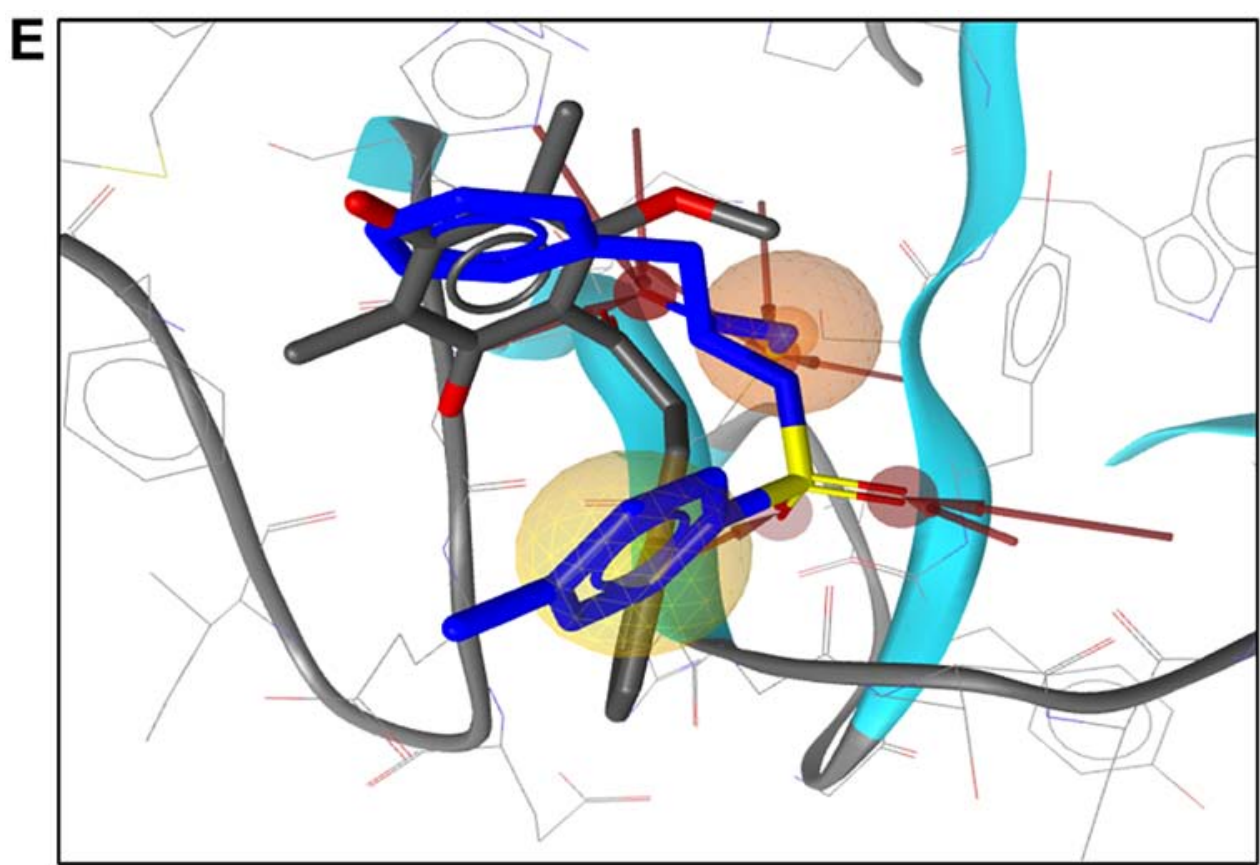

Figure 4. Pharmacophore models. Pharmacophore models of (A) MB and (B) ChalcEA in 2D and (C) MB and (D) ChalcEA in 3D. (E) Corresponding confirmation of ChalcEA that was observed in the caspase-3 structure by AutoDockTools version 1.5.6. ChalcEA, 2',4'-dihydroxy-6'-methoxy-3',5'-dimethylchalcone; MB, 4-methyl-benzenesulfonamide. 
applied against caspase receptors for the treatment of lung cancer, and it was revealed that ChalcEA serves as a caspase-3 inducer. The 3D structure of PDB ID: 2XYG was obtained from RCSB PDB (Fig. 4A). In a previous study, Ganesan et al (21) clarified that 4-methyl-benzenesulfonamide (MB) (PDB ID: 2XYG) is an inhibitor against caspase-3. MB was a rotation of the Tyr204 side chain, which blocks the S2 subsite. S2 subsite is stabilized by hydrophobic contacts with Cys163, Trp206 and Phe25. ChalcEA was docked well toward caspase-3. Notably, ChalcEA (-6.53 kcal $/ \mathrm{mol})$ could compete better than MB (-6.43 kcal/ mol; Table I). That means that the bond between ChalcEA and caspase-3 is stronger than MB, which functions as a caspase-3 inhibitor (21). ChalcEA is stabilized by water and accommodated by Gly122 and Gly165 as well as MB (19). As shown in Fig. 4B and D, ChalcEA formed hydrogen bond interaction with His121, Cys163, Tyr166 and Arg207. The interactions were stabilized by $\pi-\pi$ interaction between aromatic rings of ChalcEA and Phe128-Met61. Therefore, it can be concluded that the hydrogen bonds formed with ChalcEA are stronger than $\mathrm{MB}$, so $\mathrm{MB}$ is unable to block the process of induction of apoptosis by ChalcEA and cancer cells going to enter apoptotic process.

Based on the current results, ChalcEA functions as a potential activator of caspase-3. This conclusion was supported by a previous study which indicated that four flavonoids (considering that ChalcEA is itself a flavonoid compound) were estimated to be promising candidates for further evaluation for lung cancer prevention (22). Furthermore, Cui et al (23) reported that consumption of vegetables, tea and wine, all of which are rich sources of flavonoids, are associated inversely with lung cancer.

The present study suggested that ChalcEA obtained from the leaves of E. aquea may be a compound with potential for development as an anticancer treatment for lung cancer therapy. The influence of ChalcEA on other pathways, such as malignancy, and the ability of cells to invade to other organs, needs to be further investigated.

\section{Acknowledgements}

The authors would like to thank Professor Unang Supratman (Laboratorium Central, Universitas Padjadjaran West Java; Indonesia), for providing all the necessary facilities to carry out the present work. The authors would also like to thank Ms. Susianti (Laboratorium Central; Universitas Padjadjaran; West Java; Indonesia) for her excellent technical support and assistance.

\section{Funding}

The present study was supported by the Universitas Padjadjaran Academic Leadership fund (grant no. 1-1-6).

\section{Availability of data and materials}

The datasets used and/or analyzed during the current study are available from the corresponding author on reasonable request.

\section{Authors' contributions}

YEH, NC, MM, RL and AS designed and performed the experiments, analyzed the data and wrote the manuscript.
$\mathrm{TRu}, \mathrm{AYC}$, IS and TRo analyzed data and modified the paper. All authors read and approved the final manuscript.

\section{Ethics approval and consent to participate}

Not applicable.

\section{Patient consent for publication}

Not applicable.

\section{Competing interests}

The authors declare that they have no competing interests.

\section{References}

1. Subarnas A, Diantini A, Abdulah R, Zuhrotun A, Nugraha PA, Hadisaputri YE, Puspitasari IM, Yamazaki Ch, Kuwano $\mathrm{H}$ and Koyama H: Apoptosis-mediated antiproliferative activity of friedolanostane triterpenoid isolated from the leaves of Garcinia celebica against MCF-7 human breast cancer cell lines. Biomed Rep 4: 79-82, 2016.

2. Jaikumar B and Jasmine R: A Review on a few medicinal plants possessing anticancer activity against human breast cancer. Int J Pharm Tech Res 9: 333-365, 2016.

3. Ferlay J, Shin HR, Bray F, Forman D, Mathers C and Parkin DM: Estimates of worldwide burden of cancer in 2008: GLOBOCAN 2008. Int J Cancer 127: 2893-2917, 2010.

4. Sakarkar DM and Deshmukh VN: Ethnopharmacological review of traditional medicinal plants for anticancer activity. Int J Pharm Tech Res 3: 298-308, 2011.

5. Kinghorn AD, Farnsworth NR, Soejarto DD, Geoffrey AC, John MP, George OU, Mansukh CW, Monroe EW, Hernán AN, Rob AK, et al: Novel strategies for the discovery of plant-derived anticancer agents. Pure Appl Chem 71: 1611-1618, 1999.

6. Kinghorn AD: The role of pharmacognosy in modern medicine. Expert Opin Pharmacother 3: 77-79, 2002.

7. Kinghorn AD, Farnsworth NR, Soejarto DD, Geoffrey AC Steven MS, John MP, Mansukh CW, Monroe EW, Nicholas HO, David JK, et al: Novel strategies for the discovery of plant-derived anticancer agents. Pharm Biol 41 (Suppl): S53-S67, 2003.

8. Diantini A, Subarnas A, Lestari K, Halimah E, Susilawati Y, Supriyatna, Julaeha E, Achmad TH, Suradji EW, Yamazaki C, et al: Kaempferol-3-O-rhamnoside isolated from the leaves of Schima wallichii Korth. inhibits MCF-7 breast cancer cell proliferation through activation of the caspase cascade pathway. Oncol Lett 3: 1069-1072, 2012.

9. Subarnas A, Diantini A, Abdulah R, Zuhrotun A, Yamazaki C Nakazawa $M$ and Koyama $H$ : Antiproliferative activity of primates-consumed plants against MCF-7 human breast cancer cell lines. E3 J Med Res 1: 38-43, 2012.

10. Subarnas A, Diantini A, Abdulah R, Zuhrotun A, Hadisaputri YE, Puspitasari IM, Yamazaki Ch, Kuwano $\mathrm{H}$ and Koyama H: Apoptosis induced in MCF-7 human breast cancer cells by 2',4'-dihydroxy-6-methoxy-3,5-dimethylchalcone isolated from Eugenia aquea Burm f. leaves. Oncol Lett 9: 2303-2306, 2015.

11. Bohl CE, Miller DD, Chen J, Bell CE and Dalton JT: Structural basis for accommodation of nonsteroidal ligands in the androgen receptor. J Biol Chem 280: 37747-37754, 2005.

12. Muchtaridi M, Syahidah HN, Subarnas A, Yusuf M, Bryant SD and Langer T: Molecular docking and 3D-pharmacophore modeling to study the interactions of chalcone derivatives with estrogen receptor alpha. Pharmaceuticals 10: 1-12, 2017.

13. Zhu XF, Xie BF, Zhou JM, Feng GK, Liu ZC, Wei XY, Zhang FX, Liu MF and Zeng YX: Blockade of vascular endothelial growth factor receptor signal pathway and antitumor activity of ON-III (2',4'-dihydroxy-6'-methoxy-3',5'-dimethylchalcone), a component from Chinese herbal medicine. Mol Pharmacol 67: 1444-50, 2005.

14. El-Awady RA,Hersi F, Al-Tunaiji H, Saleh EM, Abdel-Wahab AH, Al Homssi A, Suhail M, El-Serafi A and Al-Tel T: Epigenetics and miRNA as predictive markers and targets for lung cancer chemotherapy. Cancer Biol Ther 16: 1056-70, 2015. 
15. Torre LA, Bray F, Siegel RL, Ferlay J, Lortet-Tieulent J and Jemal A: Global cancer statistics, 2012. CA Cancer J Clin 65: 87-108, 2015

16. Gutierrez RMP, Ramirez AM and Sauceda JV: Review: Potential of chalcones as a source of drugs. Afr J Pharm Pharmacol 9: 237-257, 2015.

17. Ye CL, Liu JW, Wei DZ, Lu YH and Qian F: In vitro anti-tumor activity of 2',4'-dihydroxy-6'-methoxy-3',5'-dimethylchalcone against six established human cancer cell lines. Pharmaco Res 50: 505-510, 2004.

18. Ye CL, Liu JW, Wei DZ, Lu YH and Qian F: In vivo antitumor activity by 2',4'-dihydroxy-6'-methoxy-3',5'-dimethylchalcone in a solid human carcinoma xenograft model. Cancer Chemother Pharmacol 56: 70-74, 2005.

19. Porter AG and Janicke RU: Emerging roles of caspase-3 in apoptosis. Cell Death Differ 6: 99-104, 1999.

20. Brentnall M, Rodriguez-Menocal L, De Guevara RL, Cepero E and Boise LH: Caspase-9, caspase-3 and caspase-7 have distinct roles during intrinsic apoptosis. BMC Cell Biol 14: 32-32, 2013.
21. Ganesan R, Jelakovic S, Mittl PR, Caflisch A and Grütter MG: In silico identification and crystal structure validation of caspase-3 inhibitors without a P1 aspartic acid moiety. Acta Crystallogr Sect F Struct Biol Cryst Commun 67: 842-850, 2011.

22. Christensen KY, Naidu A, Parent ME, Pintos J, Abrahamowicz M, Siemiatycki J and Koushik A: The risk of lung cancer related to dietary intake of flavonoids. Nutr Cancer 64: 964-974, 2012.

23. Cui Y, Morgenstern H, Greenland S, Tashkin DP, Mao JT, Cai L, Cozen W, Mack TM, Lu QY and Zhang ZF: Dietary flavonoid intake and lung cancer-a population-based Case-control study. Cancer 112: 2241-2248, 2008.

This work is licensed under a Creative Commons Attribution-NonCommercial-NoDerivatives 4.0 International (CC BY-NC-ND 4.0) License. 